\title{
Mineralogical and Micro-structural Investigation into the Mechanical Behaviour of a Soft Calcareous Mudstone
}

\author{
D. Simpson ${ }^{1,3} \cdot$ M. Rouainia ${ }^{1}$ (I) G. Elia ${ }^{2}$
}

Received: 21 April 2020 / Accepted: 28 February 2021 / Published online: 31 March 2021

(c) The Author(s) 2021

\begin{abstract}
The construction industry in Abu Dhabi is thriving and its coastline has some of the most ambitious structures in the world. Whilst the subsurface evaporitic and calcareous soft rocks of this region are of great geological interest, they are relatively poorly understood from a geotechnical engineering perspective, forcing foundation designs to be overly conservative. Understanding the stiffness of the underlying geology at small strains is of great importance for the accurate estimation of ground movements around excavations and foundations, and yet routine post-SI laboratory testing programmes tend to focus on basic rock mechanics tests such as UCS tests. These procedures are generally unsuitable for use with calcareous rocks due to their friable and moisture sensitive nature, and rarely obtain parameters representative of actual in situ behaviour. The calcareous mudstone investigated in this paper has mechanical and structural characteristics falling between those of a soil and those typical of a rock and, as such, requires a geotechnical testing approach that combines methods from both soil and rock mechanics disciplines. The mineralogical, micro-structural and mechanical characteristics of this lithology have been examined via a suite of testing techniques, including XRPD, SEM, advanced triaxial with bender elements, along with industry standard procedures. Shearing, tensile and consolidation behaviours have been explored. Examination of the micro- and macro-scale features of this material shows it to be highly structured, with strength and stiffness being controlled by inter-granular bonding of Dolomite grains, as well as by mean effective stress state and rate of strain. The presence of fibrous Palygorskite acts to reduce the degree of bonding, causing specimens rich in this clay mineral to have a more ductile mechanical behaviour.
\end{abstract}

Keywords Calcareous mudstones $\cdot$ Soft rocks $\cdot$ Small-strain stiffness $\cdot$ XRD $\cdot$ SEM

\section{Introduction}

Many of the coastal areas of Abu Dhabi in the United Arab Emirates (UAE) are heavily built up urban conurbations and Abu Dhabi Island is home to some of the tallest buildings in the world. The young soft rocks that make up the subsurface of this part of the Middle East are well studied from a geological standpoint. However, research into

M. Rouainia

M.Rouainia@ncl.ac.uk

D. Simpson

d.simpson@cundall.com

1 School of Engineering, Newcastle University, Newcastle upon Tyne NE1 7RU, UK

2 Technical University of Bari, Via Orabona 4, 70125 Bari, Italy

3 Present Address: Cundall Johnston \& Partners LLP, Regent Farm Road, Newcastle upon Tyne NE3 3AF, UK their complex mechanical behaviour is less common (Cook 1999; Epps 2011). The geotechnical properties of the soft rocks encountered around the Abu Dhabi coastline are often poorly understood and their unique physical characteristics cause problems when attempting to sample and test them, making the application of many standard laboratory testing methodologies inappropriate (Wright et al. 1999; Kanji 2014). This ultimately leads to overly conservative geotechnical design solutions being used to compensate for characteristic uncertainties.

Since the end of the Palaeozoic, the climate of the UAE has remained broadly similar to that of the present day, with its solid and drift geology defined by repeated cycles of glacio-eustatic triggered marine transgressions in and around the Arabian Gulf and subsequent sub-aerial erosion and transportation (Walkden and Williams 1998). These cycles have allowed the formation of vast areas of carbonate and evaporite sediments from the Gulf's saline waters, including fossiliferous limestones and dolomites along with siltstones, 
sandstones and inter-bedded gypsum, halite and anhydrite as well as the calcareous mudstones studied in this paper (Walkden and Williams 1998; Evans et al. 1973).

These mudstones were likely deposited within a low energy but chemically dynamic hyper-saline environment, and are predominantly biogenic/chemical in origin, as opposed to purely detrital. In lithologies such as these, the time gap between the formation of clasts and their bonding materials can be small, or even occur contemporaneously. Weak cementitious bridges may precipitate within voids far more rapidly than, for example, the formation of iron oxide or alumina bonds in terrestrial and freshwater sediments, introducing a degree of structure that needs to be taken into account when attempting to characterise their behaviour (Aversa and Evangelista 1998; Epps 2011; Truong et al. 2012; Fereidooni 2016). Sediments formed in hyper-saline waters are noted to be particularly sensitive to changing physico-chemical environments, which can further complicate the process of carrying out routine geotechnical laboratory tests (which typically demand full saturation), or rock testing procedures (often requiring samples to be dry (Burland and Lord 1970; Hawkins 1998)). As effective stress triaxial tests are carried out on fully saturated samples (often using deaired water), it is important that the minerals making up the samples do not dissolve over prolonged exposure to water (Jeong et al. 2007; Ciantia et al. 2015).

The young soft rocks of this study contain a percentage of evaporite minerals within their granular/cement structure that are susceptible to dissolution. Therefore, the sensitivity of these soft rocks to water ingress must be assessed and the type and quantity of the dissolvable minerals (as well as non-soluble minerals) within the soft rock structure must be understood (Liu et al. 2019). In addition, the calcareous mudstones investigated in this work are highly friable and even brittle at lower moisture contents, making the measurement of local deformations using standard strain gauges designed for application to hard rocks (or even apparatus designed for soils) particularly difficult (Lagioia and Nova 1995; Lagioia et al. 1998).

This paper presents both the methodologies and findings of a custom suite of characterisation, optical and mechanical tests carried out upon one extensively occurring soft rock lithology from the Abu Dhabi coastline. In particular, a testing programme including the use of X-ray Powder diffraction (XRPD) and scanning electron microscopy (SEM), along with standard soil and rock characterisation tests is described in the paper (1) to better highlight the degree to which dissolution may be occurring; (2) to gain insight into the mineralogy of these soft rocks and their cementing agents; (3) to assess and characterise their physical and mechanical properties, with a particular focus on the smallstrain stiffness behaviour in triaxial compression. This is of particular relevance to the design of tall buildings and underground structures in the region.

\section{Site Description and Geological Setting}

The geology of the area around Abu Dhabi Island is highly variable both laterally and vertically due to the past and present dynamic sedimentary environment (Kässler 1973). Water salinity is high and average water depth low, producing a system capable of precipitating carbonates and evaporites rapidly within a short geological timescale. This area is being heavily developed with ambitious construction projects, and yet serious engineering concerns ranging from corrosive and aggressive groundwater, dissolution of evaporites/associated subsidence (often triggered by anthropogenic activities such as ground-source heating/cooling) and piling through Caprock continue to complicate design (Epps 2011). The calcareous mudstone studied was formed in a low energy, hyper-saline environment, with a modern analogy being the area's lagoonal terraces. Significant thicknesses of this material are noted across the area of study, often interbedded with gypsum. Samples tested in this paper arose from two site investigations in Abu Dhabi. The two sites are close to one another from a geological standpoint, and they are both underlain by similar superficial deposits and solid geology. The full extents of the sites are shown in Fig. 1, and the sites will be referred to as Site 1 and Site 2 .

\subsection{Site 1}

This investigation covered a long, narrow stretch of land, and the nature of the paleogeography (comprising islands, lagoons and channels) resulted in a laterally discontinuously layered geology. Figure 1a shows a representative cross-section of Site 1. Generalised ground conditions encountered can be summarised as follows: medium dense to dense, poorly graded silty sand with occasional cemented layers, overlaying weak to very weak sandstone/calcarenite layers. Below this, a weak mudstone, inter-bedded with gypsum, is encountered. Both on-land and offshore boreholes were undertaken and produced cores of approximately $76 \mathrm{~mm}$ diameter. Cores were generally carried out in run lengths of $2.50 \mathrm{~m}$, with total core recovery of between 90 and $95 \%$ within beds where sub-samples were taken.

\subsection{Site 2}

This site is located to the south of Site 1, and ground conditions are described as medium dense, silty, gravelly, fine 
(a) Site 1
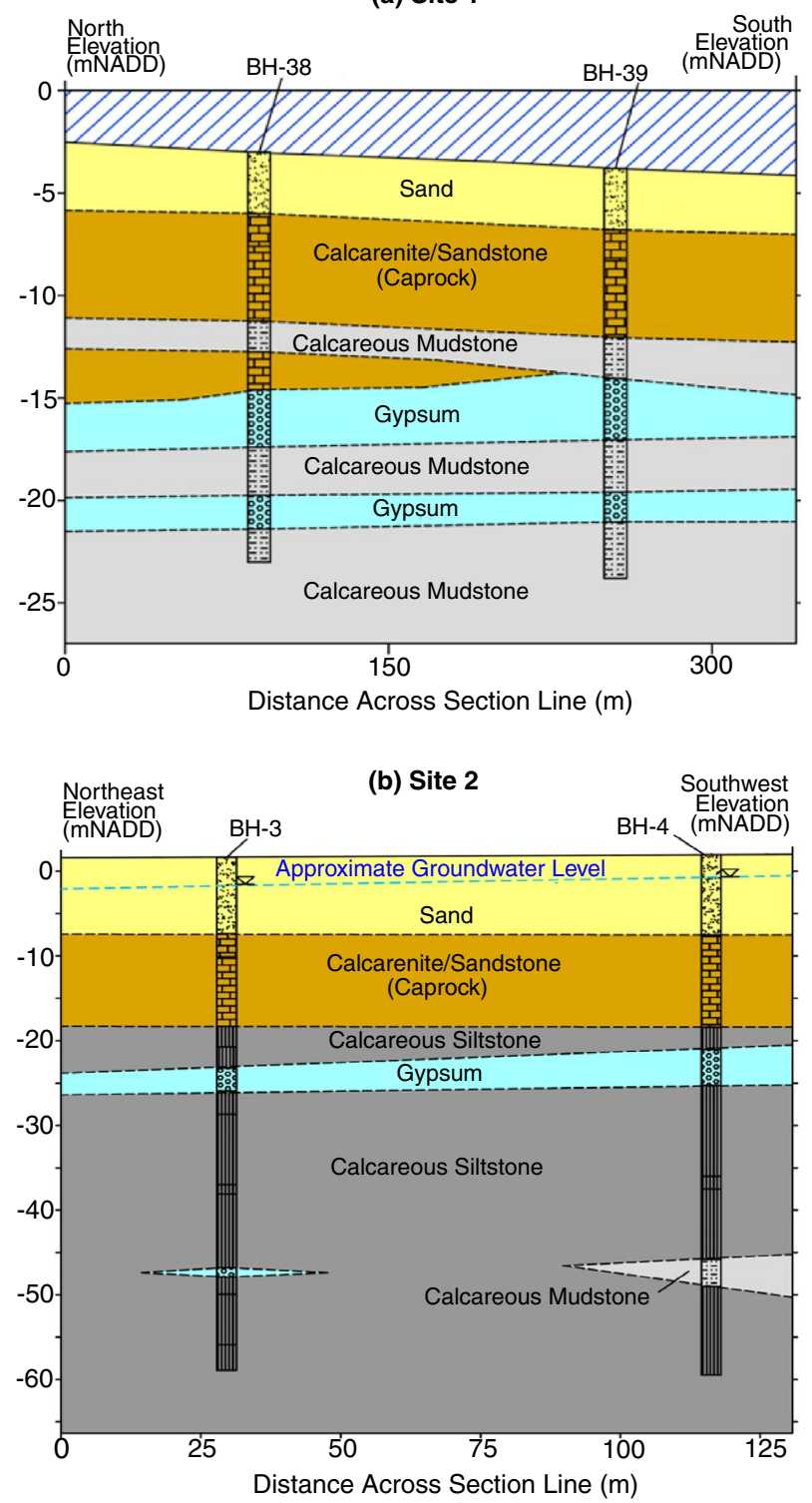

Fig. 1 Cross-sections for $\mathbf{a}$ Site 1 and $\mathbf{b}$ Site 2

to medium siliceous carbonate sand overlaying extremely weak to very weak sandstone/calcarenite. The deepest layer encountered is described as an extremely weak to very weak siltstone inter-bedded with gypsum and mudstone, which continues to the full depth of the exploratory holes. Figure $1 \mathrm{~b}$ shows a representative cross-section of Site 2. It should be noted that the material logged as siltstone at Site 2 is mechanically and characteristically similar to that of the mudstone layers noted at Site 1. Indeed, particle size distribution tests and plasticity indices confirm their comparable nature and predominantly clay sized grains. For the purpose of clarity, the soft rock referred to as mudstone at Site 1 and erroneously as siltstone at Site 2 will be referred to as calcareous mudstone going forwards, as this designation better describes the material of interest within this paper.

\section{Experimental Results}

Eight core runs of the calcareous mudstone were obtained from boreholes within Site 1 along with eight core runs from Site 2, from which sub-samples were extracted for the various experimental testing as required. Whilst all calcareous mudstone cores appeared superficially similar, preliminary testing revealed that samples could be reliably divided into two distinct sub-types (namely Type A and Type B) based upon their behaviour and characteristics. For example, Type A samples failed in triaxial compression following a high peak stress with a high stiffness, whilst Type B samples failed at larger strains and lower stresses under the same conditions. On this basis, specimen names have been simplified as A1 through A9 for Type A materials and B1 through B7 for Type B materials for ease of reading, and all samples have been subjected to a broad suite of experimental testing, the results of which are presented in this paper ordered from micro to macro. Optical techniques such as XRPD and SEM are presented first, as they focus on very small-scale features, followed by the results of standard characterisation tests and ultimately the findings of advanced triaxial tests.

\subsection{Petrographic Study: XRPD}

Two sets of qualitative XRPD tests on powdered bulk samples were carried out to characterise both mineralogy and the potential effect of dissolution. A PANalytical X'Pert Pro Multipurpose Diffractometer (fitted with an $\mathrm{X}^{\prime}$ Celerator and secondary monochromator) was used to identify likely mineral phases present within the calcareous mudstone. Samples were scanned in continuous mode using the X'Celerator RTMS detector. Samples displaying both Type A and Type B behaviour were selected to see if a mineralogical discrepancy might account for their mechanical differences. In addition, sub-samples of all specimens were prepared by exposing them first to flowing deionised water, to assess the effect of dissolution on a mineralogical scale.

XRPD results are shown in Fig. 2a and $b$ with notable mineral phases highlighted and notable 2-Theta angle peaks annotated. However, it should be noted that not all mineral 2-Theta peaks appear on this image for the sake of readability. All samples show similar mineralogical finger prints, displaying comparable peak angles and peak heights between samples taken, indicating that they are 

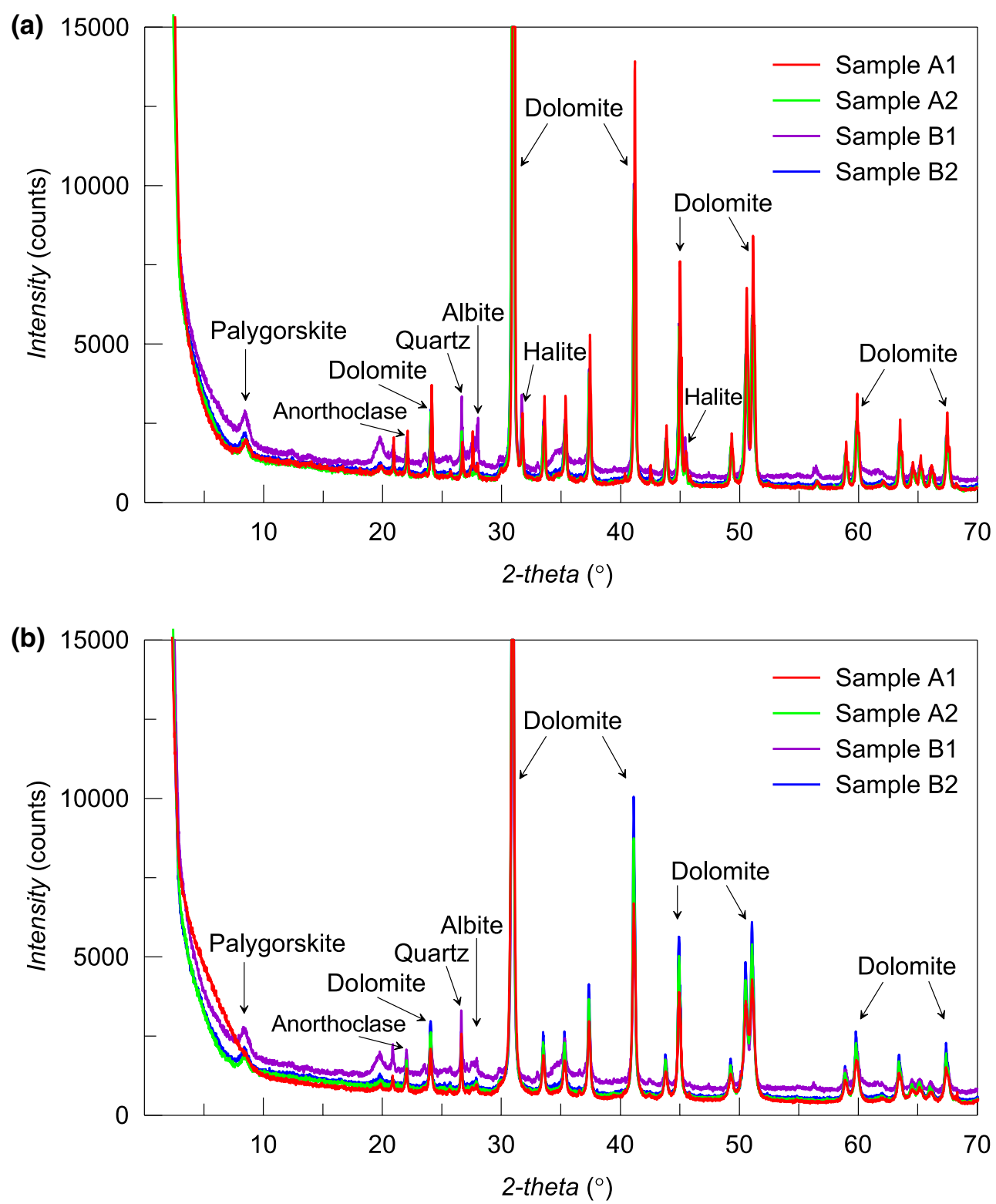

Fig. 2 XRPD analysis for all $\mathbf{a}$ natural and $\mathbf{b}$ washed samples of calcareous mudstone

qualitatively composed of similar minerals. Results reveal the presence of Albite, Anorthoclase, Quartz, Halite and the clay mineral Palygorskite in all samples. However, Dolomite is clearly the prevailing mineral type with very high intensity counts. Interestingly, no Calcite is noted in any of the samples tested. No Gypsum or Anhydrite is detected in any of the samples tested, despite the in situ proximity of the sample cores to known gypsum beds.

Dolomite is a common mineral to be found associated with sediments and rocks formed in hyper-saline water bodies. However, its method of formation is a great source of controversy within the literature, as Dolomite is not forming today at the earth's surface except within extreme environments such as hot springs (Eugster and Hardie 1978; Last 1990; Sanz-Montero et al. 2006). Although the aim of the work is not to explain the origin of the Dolomite deposits at the studied sites, it is interesting to note the variety of processes and theories that might be responsible for its presence, ranging from the replacement of Calcite and Gypsum by Dolomite to the microbially mediated precipitation of Dolomite by algae and sulphate-reducing bacteria (Pierre and Rouchy 1988; Machel 2001; Sanz-Montero et al. 2006). The minor quantities of Quartz and Feldspars present in the XRPD analysis are likely to be due to occasional grains of 
Table 1 Summary of Rietveld analysis on calcareous mudstone samples

\begin{tabular}{llllll}
\hline Sample reference & Dolomite $(\%)$ & Quartz $(\%)$ & Halite $(\%)$ & Palygorskite (\%) & Strength designation $^{\mathrm{a}}$ \\
\hline A6 & 88.0 & 1.0 & 1.8 & 9.2 & Type A \\
A9 & 89.0 & 4.0 & 2.5 & 4.5 & Type A \\
B1 & 73.0 & 1.1 & 2.9 & 23.0 & Type B \\
B7 & 73.0 & 6.9 & 2.4 & 17.7 & Type B \\
B5 & 84.0 & 3.6 & 2.0 & 10.4 & Type B \\
B6 & 82.0 & 2.0 & 2.0 & 14.0 & Type B \\
\hline
\end{tabular}

${ }^{a}$ From correlation with mechanical data detrital debris, transported from an adjacent high energy sub-environment into the low energy sub-environment that allowed the carbonate muds to form. Halite is also present in samples which have not been exposed to flowing deionised water (Fig. 2a), likely present due to the recent precipitation of residual saline pore-water from the sample drying during preparation for testing, although the potential for crystalline Halite existing within the calcareous mudstone's structure cannot be ruled out. Halite is not seen in samples that have been exposed to flowing deionised water (Fig. 2b), owing to its dissolvable nature, potentially creating problems during effective stress triaxial tests which require samples to be saturated, typically with deaired deionised water. One mineral of significant interest is Palygorskite, which is present in all samples. Palygorskite is a hydrous magnesium alumina (and iron) silicate, a fibrous clay mineral, the origin of which is debated at length within the literature (Haydn and Huitang 2005).

Palygorskite, sometimes known as Attapulgite, is a member of the Hormite family of clays and has many industrial uses, due to its sorptive capacity, including lubricants, adhesives, paints and pharmaceuticals (Haydn and Huitang 2005; Rhouta et al. 2013). It tends to be found in carbonate sedimentary rocks and sediments deposited in high temperature/salinity marine/lagoonal waters (Isphording 1973; Rodriguez-Navarro et al. 1998; Machel 2001; Rhouta et al. 2013) as well as forming in peri-marine and non-marine environments by detrital sedimentation under varying salinity conditions. Stagnation of the source water, along with its alkalinity, the presence of $\mathrm{Si}$ - and $\mathrm{Mg}$-rich fluids and intense evaporation are all considered to be critical to its formation (Inglès and Anadón 1991). The modern-day lagoons around the Abu Dhabi coast fluctuate in temperature and salinity throughout the year and, whilst some are connected to the main body of the Arabian Gulf, others are isolated allowing them to become hyper-saline. It is likely that these conditions were also present in the environments that formed the soft rocks of this study and that localised high concentrations of Palygorskite may have occurred within the carbonate muds prior to their lithification. The highest peak indicating Palygorskite during XRPD analysis, like many clay minerals, occurs at a low 2-Theta angles. Within this region there is much noise associated with the limitations of the test itself, making Palygorskite difficult to quantitatively measure.

XRPD analysis is concluded as being unable to highlight any mineralogical difference between the Type A and Type B material types, meaning that any differences must be due to the relative abundances of the minerals present and not due solely to the presence or lack of specific minerals.

Quantitative XRPD tests on powdered bulk samples were, therefore, carried out to characterise the samples mineralogy. Samples were again selected from the Type A and Type B specimens to ascertain if changes in the relative abundance of minerals might account for the mechanical differences noted during preliminary triaxial tests. Semi-quantitative Rietveld refinement was used to quantify the relative abundances of minerals by examination of the peak shape and size during XRPD analysis (Rietveld 1969), the results of which are summarised in Table 1 and reveal that the Type A samples have overall higher percentage fractions of Dolomite (with an average of $88.5 \%$ ) and lower percentages of Palygorskite (on average equal to 6.9\%), whilst having similar amounts of Quartz and Halite to the Type B samples. The Type B samples, by contrast, have significantly lower percentages of Dolomite (average of 78.0\%), but higher amounts of Palygorskite (on average equal to 16.3\%). These trends correspond well to the findings of the PSD analysis where upon Type B samples have a greater percentage of clay sized grains than Type A specimens.

\subsection{Petrographic Study: SEM}

SEM analysis was performed to corroborate the findings of the XRPD study and to obtain high resolution, high magnification images of the minerals present to qualitatively assess their relative abundances and observe their 3D micro-structure, with an aim to compare Type A and Type B samples. The study required the preparation of small broken fragments, approximately $1 \mathrm{~cm}^{3}$ in size and displaying at least one fresh rough surface. To maximise image clarity and resolution, samples were gold coated.

Rounded (peloidal), fused Dolomite grains can be clearly observed, for example in sample A1 (Fig. 3), along with 
occasional rhombic grains. It is likely that the tightly bonded subhedral peloids (rounded, fused grains) are the remains of a partially dissolved interlocking mosaic, a common feature in carbonate diagenesis caused by neomorphism (Mazzullo 1992; Jameson 1992). The rhombic shaped grains (rhombs) are likely to be partially dissolved Dolomite, as rhomboid shapes are a common Dolomite crystal form (Sanz-Montero et al. 2006) and no calcite was present during XRPD analysis.

High-resolution SEM images successfully highlighted significant differences between Type A and Type B samples in terms of both their structure and the presence (or lack) of the inter-clast clay mineral Palygorskite. A clear example of this is shown in Fig. 4 by comparing a typical Type A sample (A2) and a Type B specimen (B2). The Type A image shows clasts of Dolomite fused tightly together with very little or no inter-clast minerals present (alpha), whereas the Type B image contains high quantities of a clay mineral with a micro fibrous morphology located both on and between clasts (beta). The fibrous clay mineral in question is believed to be Palygorskite, as suggested by the XRPD analysis and due to its superficial morphology being markedly similar to that of the Palygorskite tested by Neaman and Singer (2000) and Rhouta et al. (2013). It appears as mono-mineralic assemblages of straight fibres at random orientations within void spaces and between larger grains and it is thought to be formed via its precipitation from solution (Singer 1981). Merkl (1989) identified that Palygorskite may appear as short length $(<10 \mu \mathrm{m})$ and long length $(>10$ $\mu \mathrm{m})$ particles, signifying low and high magnesium content, respectively (Haydn and Huitang 2005).

At high magnifications, as shown in sample B5 (Fig. 5), several samples are noted to contain areas covered in frequent hollows, through which the underlying fibrous
Palygorskite may be seen and the grains themselves are texturally rough, as opposed to amorphous. The Dolomite appears to have grown over the Palygorskite fibres (overgrowths), again likely due to processes of neomorphism (Jameson 1992). The existence of Palygorskite filled hollows supports the hypothesis that the clay mineral is stopping the Dolomite grains from fusing fully.

\subsection{Characterisation Tests: Atterberg Limits}

Atterberg limits were carried out according to BS1377-2 (1990) primarily to distinguish between Type A and Type B specimens. Liquid and plastic limits show the calcareous mudstones encountered in both sites to be highly comparable (see Table 2). Type A and Type B samples form tight clusters of data points, irrespective of depth or location, with few outliers. Type A samples have a mean plastic limit of $23.8 \%$, liquid limit of $40.6 \%$ and a mean plasticity index of $16.8 \%$, designating them as being of intermediate to low plasticity. Type B samples have higher values of plastic and liquid limit, equal on average to 27.7, $52.4 \%$, respectively, and therefore, a higher average plasticity index of $24.7 \%$, classifying them as an intermediate to high plasticity material. This increase in plasticity is interpreted to be a result of higher concentrations of Palygorskite in Type B samples, supporting the findings of the SEM analysis. The classification of the soils according to the Casagrande plasticity chart is shown in Fig. 6.
Fig. 3 SEM analysis of sample A1

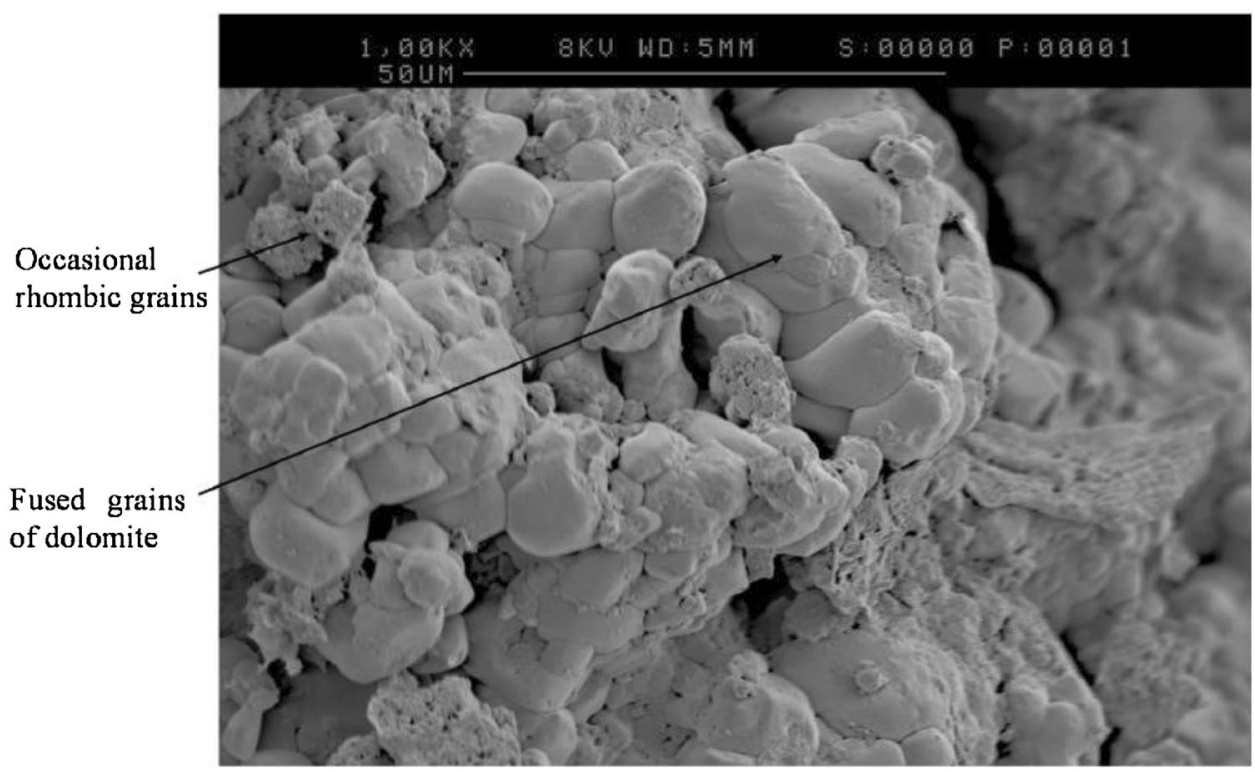




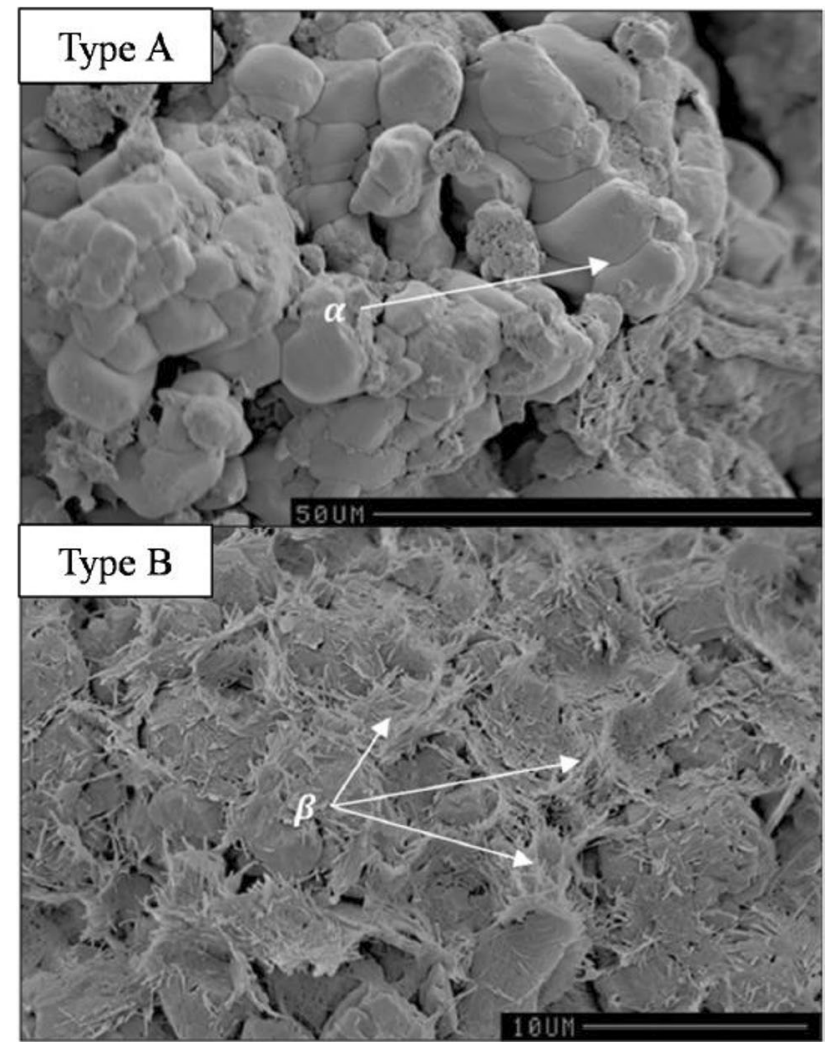

Fig. 4 SEM analysis of a Type A sample (A1), displaying inter-clast fusing of Dolomite, and a Type B specimen (B2) showing a high percentage of inter-clast fibrous Palygorskite and smaller grain size

\subsection{Characterisation Tests: Particle Size Distribution, Dispersivity and Slake Durability Tests}

PSD tests were carried according to BS1377-2 (1990) on samples from both sites, with those from Site 1 reported in Fig. $7 \mathrm{a}$ and those from Site 2 reported in Fig. 7b. Samples have between 97.3 and $100 \%$ fine particles (less than $63 \mu \mathrm{m}$ in diameter) from both sites, with clay fraction between 15 and $40 \%$, depending upon specific sample. Type B samples have, on average, $9.1 \%$ more grains passing the $0.002 \mathrm{~mm}$ particle size and less coarse silt sized particle than those of the Type A samples. PSD tests corroborate the findings of the SEM and Atterberg analysis in that Type B samples have a significantly higher fraction of grains smaller than $24 \mu \mathrm{m}$ than those of Type A samples.

Dispersivity (Crumb) tests performed following BS1377-5 (1990) indicate the material to be highly sensitive to the presence of water in unconfined conditions, breaking down almost entirely within a short time period and producing colloids. This feature is confirmed via slake durability testing (Franklin and Chandra 1972; Brown 1986; ASTM 1990; ISRM 1979) which shows both very low first (32-38\%) and second cycle (1-5\%) durability indices (ID) of both the Type A and Type B materials from both sites, with no significant differences between materials being noted (Results summary shown in Table 3 ). Whilst this occurs for samples under zero confining pressure, it has not been observed on a macro-scale during preliminary triaxial testing under confining stress, despite samples being fully saturated.
Fig. 5 SEM analysis of sample B5 showing a high magnification image of Palygorskite within Dolomite

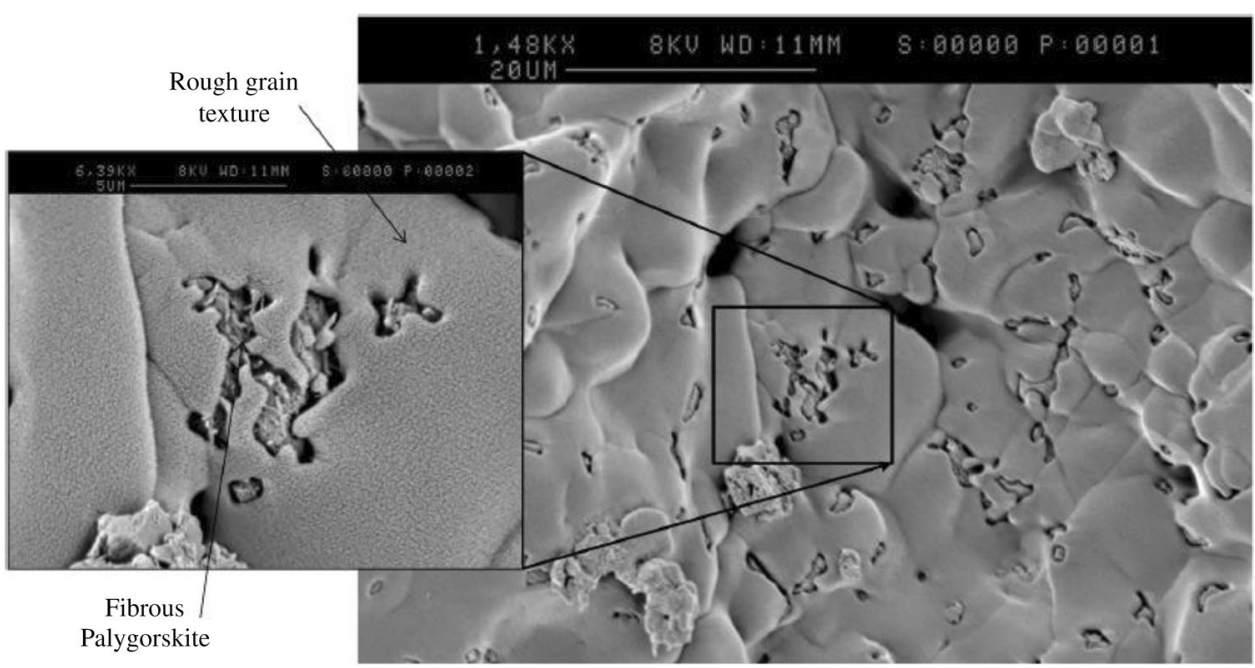


Table 2 Summary of Atterberg limit tests

\begin{tabular}{lllll}
\hline Sample reference & Plastic limit $(\%)$ & Liquid limit $(\%)$ & Plasticity index $(\%)$ & Plasticity designation \\
\hline A1 & 24.0 & 42.9 & 18.9 & CI \\
A2 & 20.8 & 32.6 & 11.8 & $\mathrm{CL}$ \\
A6 & 23.3 & 42.3 & 19.0 & $\mathrm{CI}$ \\
A8 & 22.4 & 39.5 & 17.1 & $\mathrm{CL}$ \\
B1 & 28.8 & 54.3 & 25.5 & $\mathrm{CH}$ \\
B3 & 26.6 & 66.2 & 39.6 & $\mathrm{CH}$ \\
B6 & 28.5 & 48.5 & 20.0 & $\mathrm{CI}$ \\
B7 & 26.2 & 53.1 & 26.9 & $\mathrm{CH}$ \\
\hline
\end{tabular}

\section{Mechanical Study}

Two sets of effective stress tests, CDTs (Consolidated Drained Triaxial), were undertaken on samples of both Type A and Type B calcareous mudstone as part of this study, the first examining the effect of changing confining stress and the second examining the effect of changing strain rate. CDT tests were conducted to investigate the long term behaviour of the soft rocks to support future designs of deep foundations at the two selected sites. The CDT tests were carried out according to the BS1377-8 (1990) albeit with slower strain rates to allow multiple data points to be obtained within the small strain and very small strain range.

\subsection{Effect of Confining Stress}

Suite of eight consolidated drained triaxial (CDT) tests were carried out upon Type A and Type B specimens. Samples were isotropically consolidated to initial mean effective stresses $\left(p_{0}^{\prime}\right)$ of $235,470,940$ and $1300 \mathrm{kPa}$ prior to shearing at a set deformation rate equal to $0.001 \%$ axial strain per minute under drained conditions. In addition, Bender Elements (BE) were employed for the measurement of small-strain shear stiffness $\left(G_{0}\right)$ at varying confining stresses. Table 4 summarises the initial properties of the samples along with the conditions under which they were consolidated and sheared.

Type A samples comprise A1, A2, A3 and A4 and Type B samples comprise B1, B2, B3 and B4. Figure 8 shows the stress-strain (a) and volumetric behaviour (b) observed during the CDT tests performed with increasing mean confining pressure. All tests on Type A samples display peak behaviour, with visual inspection of samples post failure revealing well defined shear planes, occurring at shear strains no greater than $1.5 \%$. Type A samples also have a significantly higher maximum deviator stress than the corresponding Type B specimens for any given initial stress state. Type B samples stop displaying peak behaviour between the 470 and $940 \mathrm{kPa} p_{0}^{\prime}$ tests and, instead, show some degree of strain hardening, ductile behaviour. Post-failure, these samples also show shear planes, although they have a more pronounced barrelling at their centre. This likely indicates the degradation of cementitious bonds as isotropic mean effective consolidation states are increased (beyond $470 \mathrm{kPa}$ ). Failure occurs in Type B samples at much greater shear strains of between 2.2 and
Fig. 6 Casagrande classification of representative samples from both sites

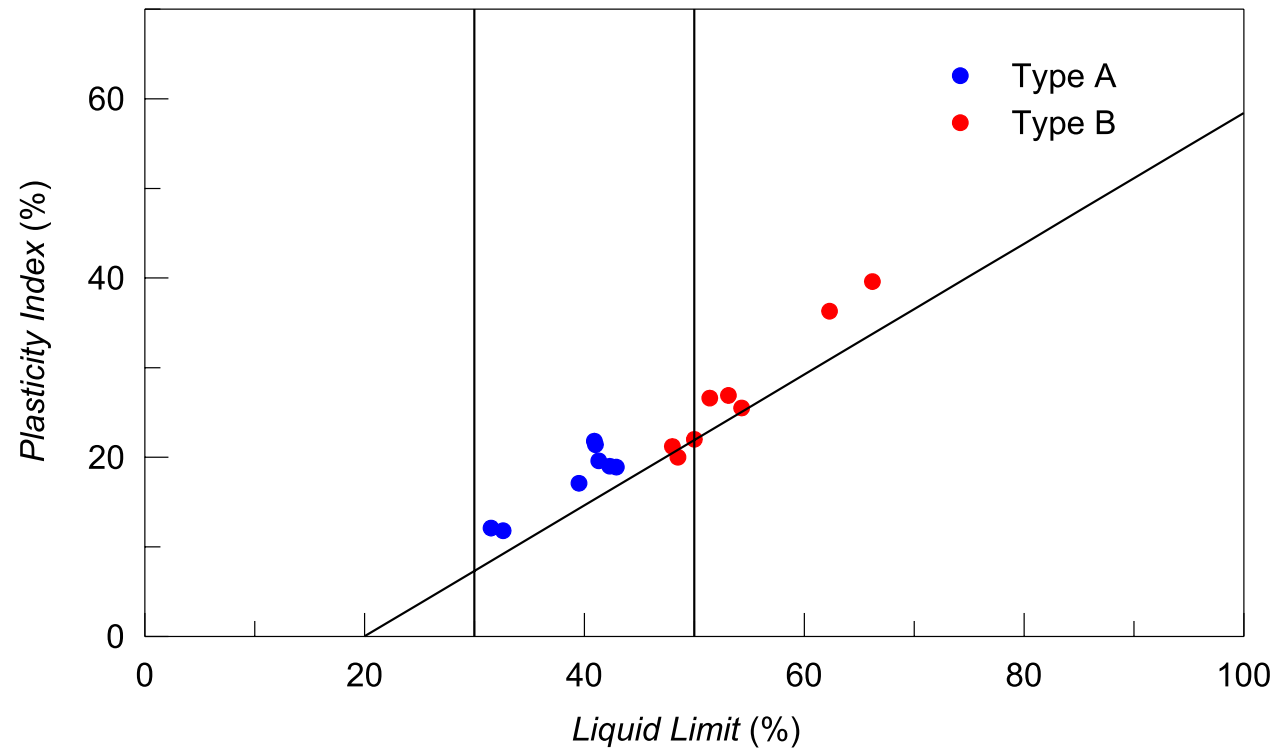


Fig. 7 PSD curves for representative samples a Site 1 and b Site 2
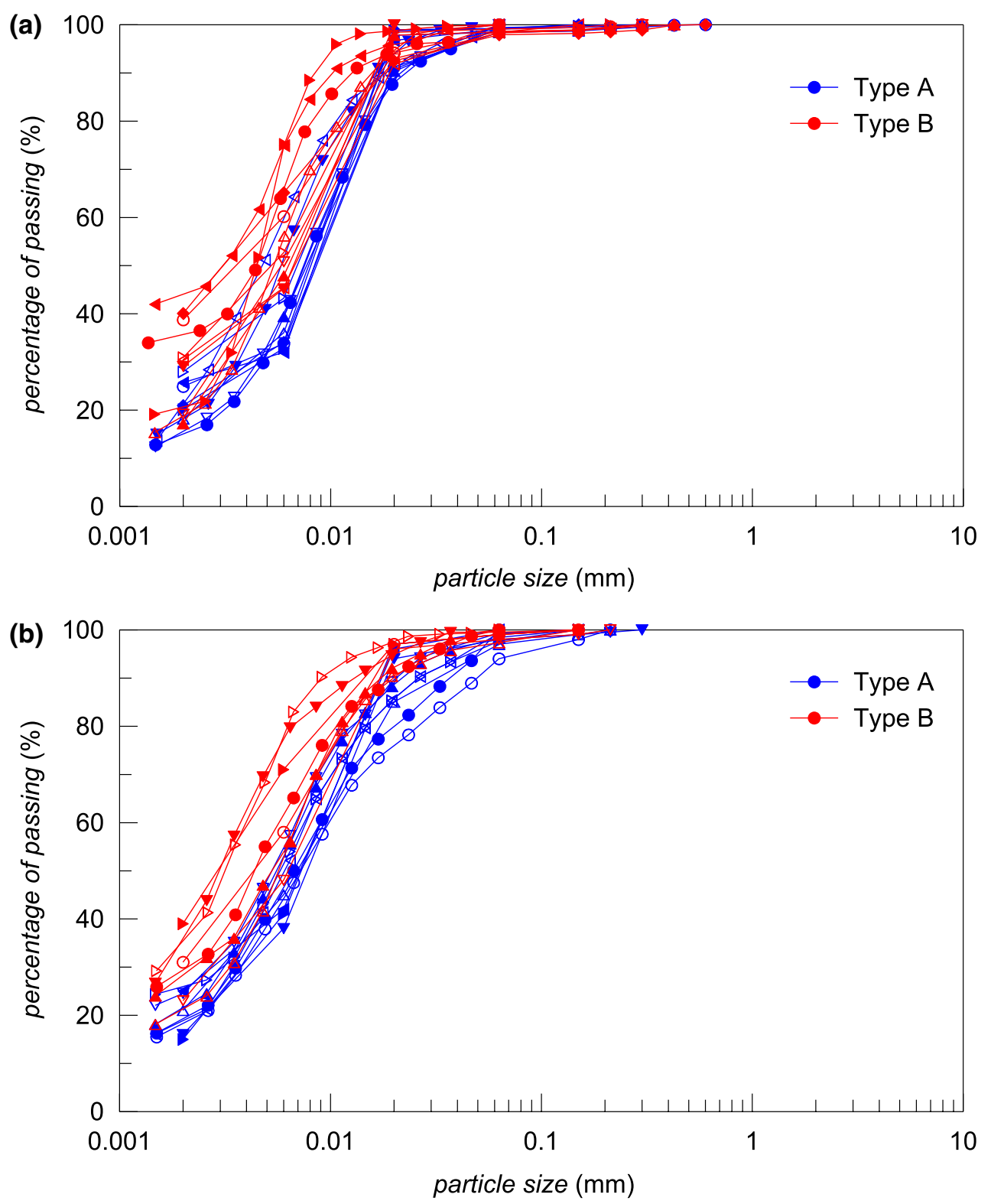

$4.5 \%$, more than double the shear strains of the Type A samples at failure from any given initial stress state. It can also be noted that the final deviator stress of any Type A sample is similar to the final value of the corresponding Type B test for a given initial stress state.

Volumetric behaviour observed during the 235, 470 and $940 \mathrm{kPa}$ Type A tests is seen to shift from being initially contractant to dilatant as shear strains increase. Only the sample A4 is noted to be purely contractant throughout the test, indicating that the high mean effective confining stresses of $1300 \mathrm{kPa}$ may have caused a degradation of the material bonding, allowing a ductile behaviour. The volumetric response of Type $B$ samples also indicates a shift from brittle to ductile behaviour as the higher mean effective stress states are reached, however this transition is seen to occur at significantly lower values of $p_{0}^{\prime}$ (as this behaviour is apparent from the $940 \mathrm{kPa}$ test onwards), corresponding to

Table 3 Slake durability testing results

\begin{tabular}{lll}
\hline Sample reference & \multicolumn{2}{l}{ Durability Index } \\
\cline { 2 - 3 } & 1st cycle $\left(\mathrm{ID}_{1}\right)$ & 2nd cycle $\left(\mathrm{ID}_{2}\right)$ \\
\hline A2 & 32.2 & 1.1 \\
A4 & 36.4 & 4.7 \\
A5 & 34.7 & 2.6 \\
B1 & 33.2 & 2.5 \\
B2 & 37.8 & 4.1 \\
B8 & 33.2 & 1.9 \\
\hline
\end{tabular}


Table 4 Summary of sample properties during CDT tests with changing confining pressure

\begin{tabular}{llllllllll}
\hline Property & Units & $\mathrm{A} 1$ & $\mathrm{~A} 2$ & $\mathrm{~A} 3$ & $\mathrm{~A} 4$ & $\mathrm{~B} 1$ & $\mathrm{~B} 2$ & $\mathrm{~B} 3$ & $\mathrm{~B} 4$ \\
\hline Initial moisture content & $(\%)$ & 20.1 & 20.3 & 17.8 & 20.1 & 20.0 & 20.1 & 20.5 & 21.5 \\
Initial bulk density & $\left(\mathrm{Mg} / \mathrm{m}^{3}\right)$ & 2.03 & 2.02 & 2.02 & 2.03 & 2.02 & 2.02 & 2.01 & 2.01 \\
Initial dry density & $\left(\mathrm{Mg} / \mathrm{m}^{3}\right)$ & 1.69 & 1.68 & 1.71 & 1.69 & 1.68 & 1.68 & 1.67 & 1.67 \\
Initial void ratio & - & 0.59 & 0.60 & 0.60 & 0.59 & 0.60 & 0.60 & 0.61 & 0.61 \\
Initial porosity & $(\%)$ & 37.3 & 37.5 & 37.7 & 37.2 & 37.6 & 37.6 & 38.2 & 38.1 \\
Initial degree of saturation & $(\%)$ & 91.10 & 91.35 & 81.04 & 91.30 & 89.80 & 90.00 & 89.50 & 94.10 \\
Mean effective stress & $(\mathrm{kPa})$ & 235 & 470 & 940 & 1300 & 235 & 470 & 940 & 1300 \\
Shearing rate & $(\mathrm{mm} / \mathrm{min})$ & & 0.0014 & & & & 0.0014 & & \\
\hline
\end{tabular}

similar observations noted in the stress-strain analysis. The interpretation of the CDT results in terms of Mohr-Coulomb failure criterion indicate that Type A samples have an effective cohesion $\left(c^{\prime}\right)$ of $400 \mathrm{kPa}$ and an effective angle of internal friction, $\phi^{\prime}$, of about $33^{\circ}$. Type B specimens display a similar $\phi^{\prime}$ of $33^{\circ}$, but a significantly lower $c^{\prime}$ equal to 200 $\mathrm{kPa}$. The lower cohesion in the Type B samples at failure is thought to be the mechanical expression of the poorer degree of bonding noted during the SEM analysis. Figure 9 presents the triaxial results in terms of stress path and stress ratio $q / p^{\prime}$ vs deviatoric strain. The failure points for both Type A and Type B are indicated by the crosses in Fig. 9a. It can be seen that both types samples show similar failure strength.

Type A samples display higher shear stiffness at lower shear strains than Type B samples tested at the same mean effective stress. The stiffness of Type A samples degrades
Fig. 8 Stress-strain and volumetric behaviour with changing mean confining pressure comparing Type A and Type B samples
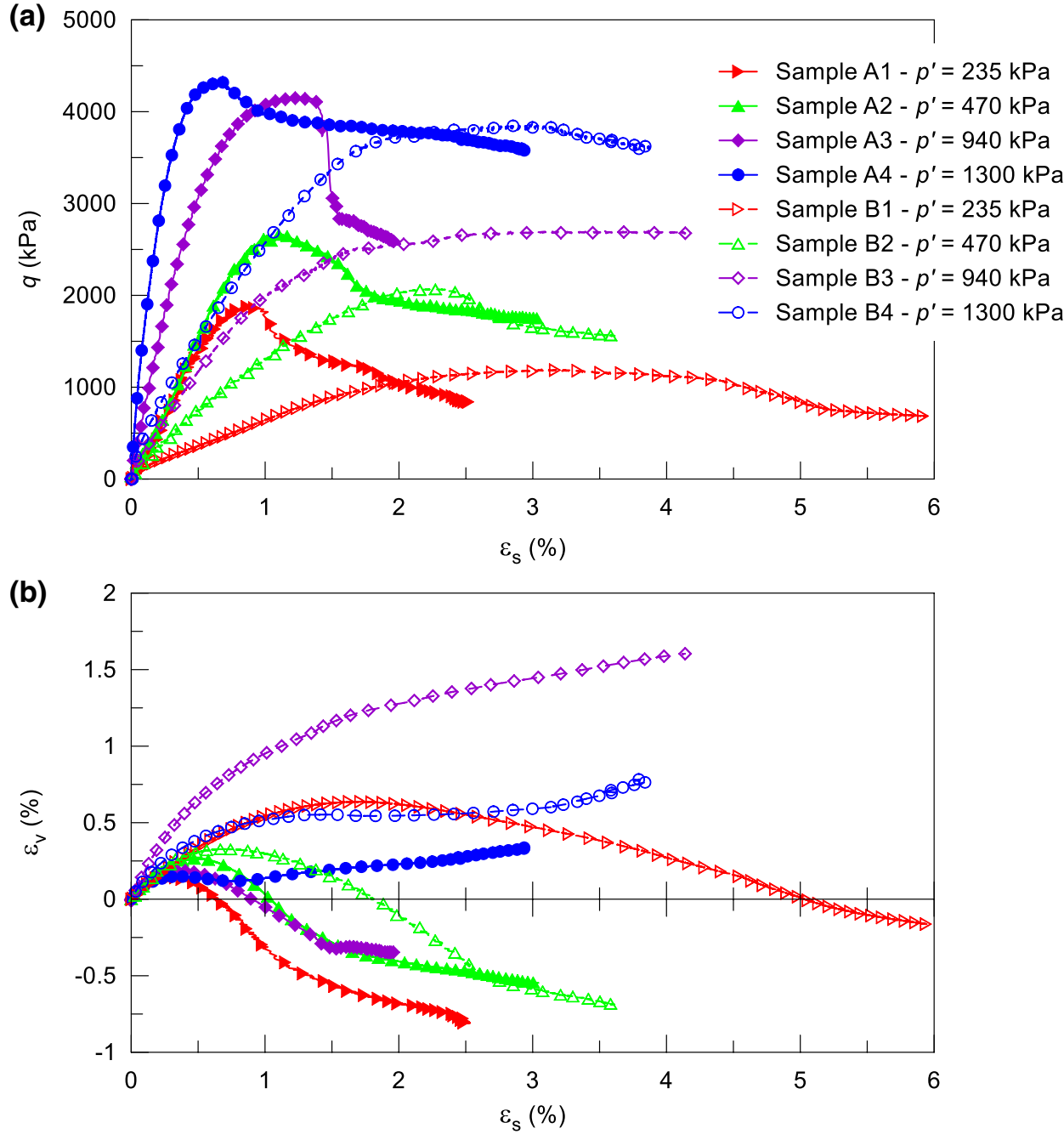
rapidly with the onset of shear strains until at around $0.04 \%$ where a reasonably steady plateau is noted in all but sample A4, creating a characteristic $S$ shaped curve (Fig. 10). The stiffness of sample A4 degrades steadily from $G_{\max }$ indicating an isotropic de-bonding caused by the high effective confining pressure, corresponding to entirely contractant volumetric behaviour. A further drop in shear stiffness is noted at between 0.6 and $1.2 \%$ shear strains, corresponding to the point immediately before peak deviator stresses are met. It is also at this point that samples consolidated to 235,470 and $940 \mathrm{kPa}$ shift from contractant to dilatant volumetric straining. Upon entering large strains, all Type A samples' stiffness converge and have a similar residual value.
Type B samples do not show the stiffness plateau noted in the Type A samples, even at low mean effective stresses. Their stiffness instead reduces at a relatively constant rate from their $G_{\max }$ without displaying the degradation pattern. Type B stiffnesses also converge at large strains. $G_{0}$ was assessed with Bender element (BE) tests performed on Type A samples. Several techniques were considered for the interpretation of these results, concluding that the 1st bump method (e.g. Viggiani and Atkinson 1995) provides an upper boundary of $G_{0}$ values, whilst the peak to peak (e.g. Jovicic and Coop 1996) and the start to start techniques give lower boundary estimates (e.g. Fonseca et al. 2009). The measured $G_{0}$ values are shown in Fig. 10 alongside Type A stiffness (a)

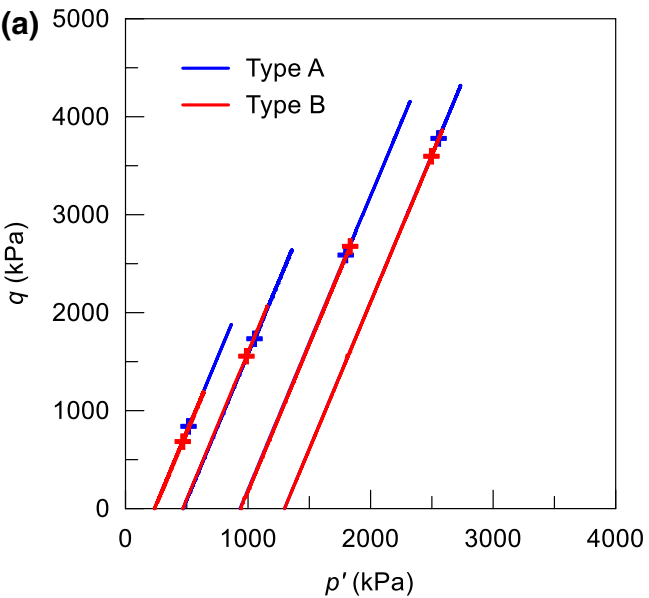

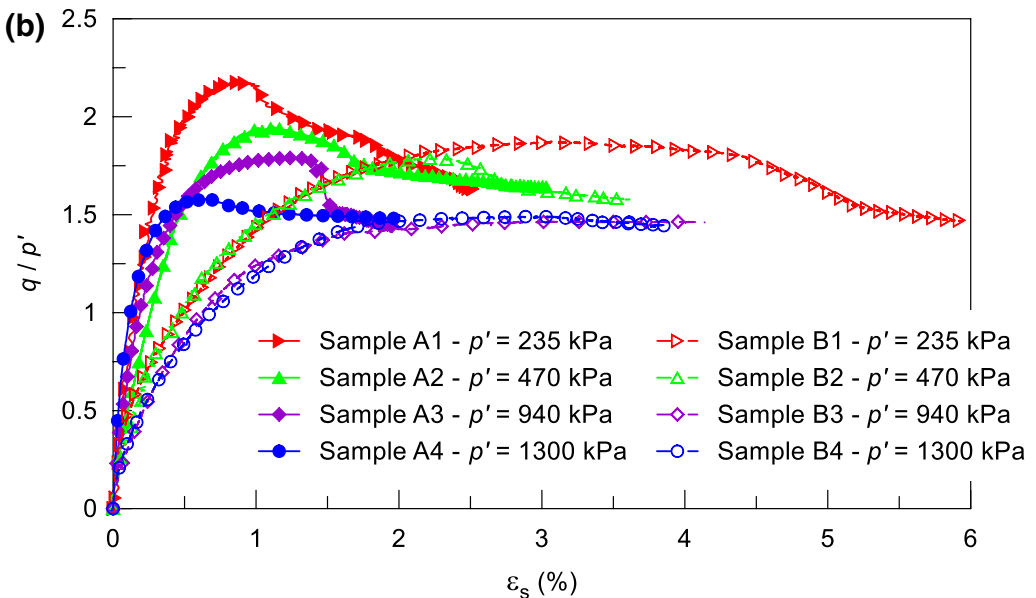

Fig. 9 Results of CDT tests reported in terms of a stress path (failure points indicated by the crosses) and $\mathbf{b}$ stress ratio $q / p^{\prime}$ vs deviatoric strain comparing Type A and Type B samples

Fig. 10 Secant shear stiffness degradation with changing mean confining pressure

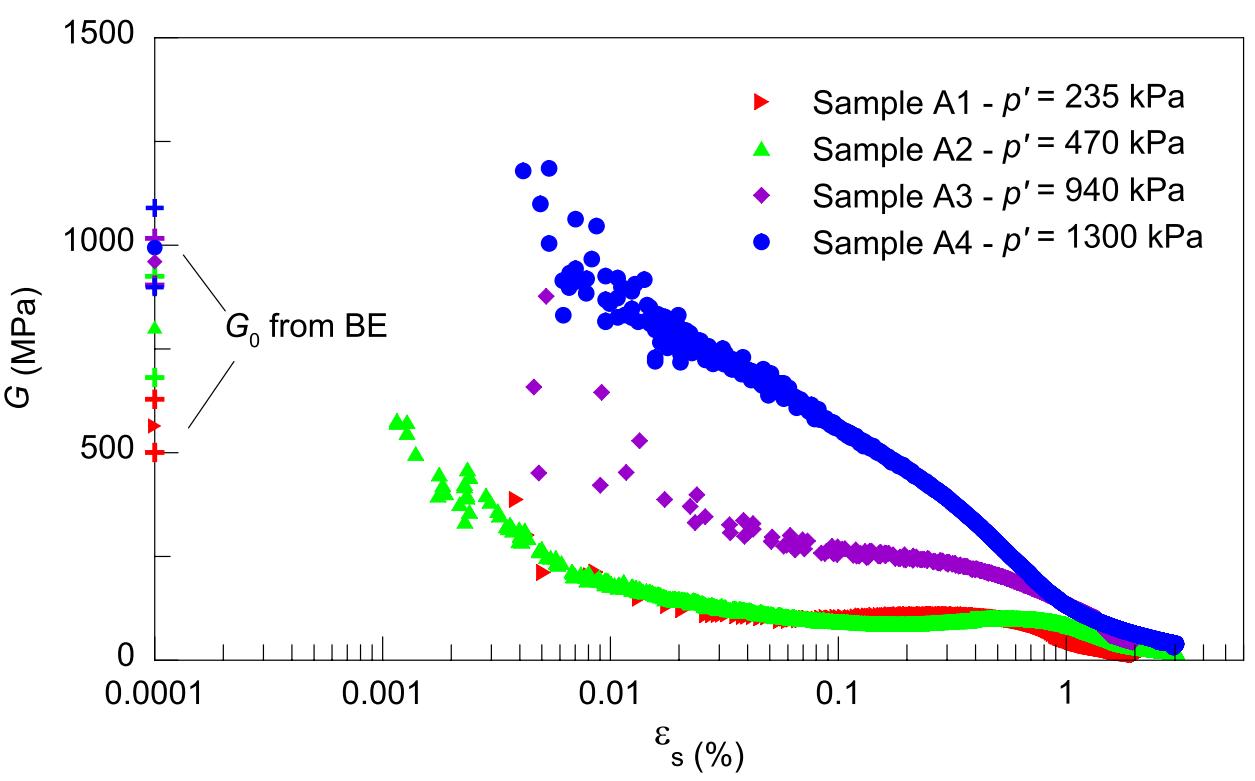


Table 5 Summary of sample properties during CDT tests with changing strain rate
Fig. 11 Stress-strain and volumetric behaviour with changing strain rate of Type B samples

\begin{tabular}{llllll}
\hline Property & Units & B3 & B5 & B6 & B7 \\
\hline Initial moisture content & $(\%)$ & 20.5 & 19.8 & 21.1 & 20.2 \\
Initial bulk density & $(\mathrm{Mg} / \mathrm{m} 3)$ & 2.01 & 2.01 & 2.01 & 2.01 \\
Initial dry density & $(\mathrm{Mg} / \mathrm{m} 3)$ & 1.67 & 1.68 & 1.66 & 1.68 \\
Initial void ratio & - & 0.61 & 0.60 & 0.62 & 0.61 \\
Initial porosity & $(\%)$ & 38.2 & 37.8 & 38.4 & 37.9 \\
Initial degree of saturation & $(\%)$ & 89.50 & 88.00 & 91.40 & 89.30 \\
Isotropic mean effective stress & $(\mathrm{kPa})$ & 940 & 940 & 940 & 940 \\
Shearing rate & $(\mathrm{mm} / \mathrm{min})$ & 0.0014 & 0.0014 & 0.00014 & 0.014 \\
Strain rate & $(\% / \mathrm{min})$ & 0.001 & 0.001 & 0.0001 & 0.01 \\
\hline
\end{tabular}
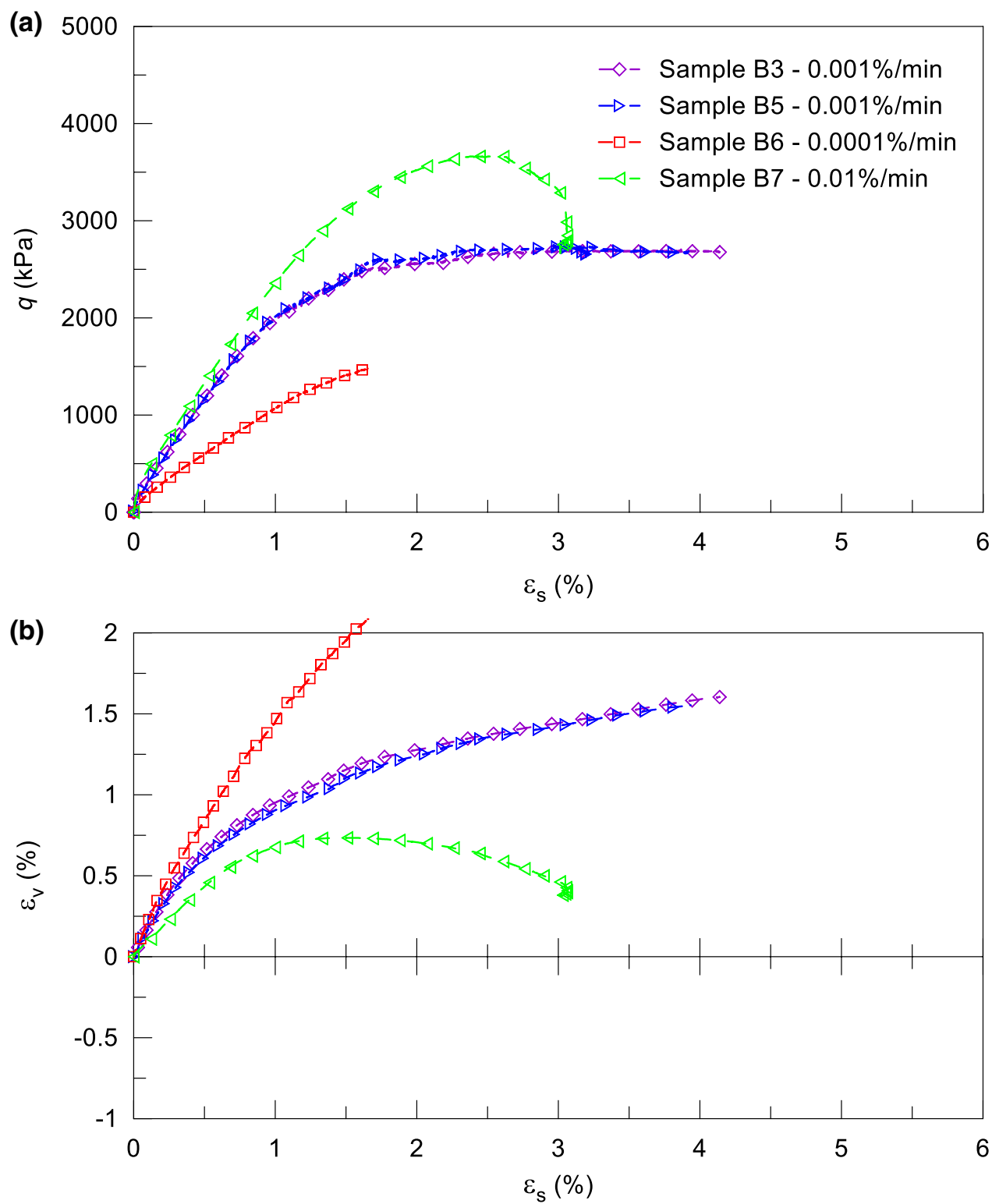
Fig. 12 Secant shear stiffness degradation with changing strain rate of Type $\mathrm{B}$ samples

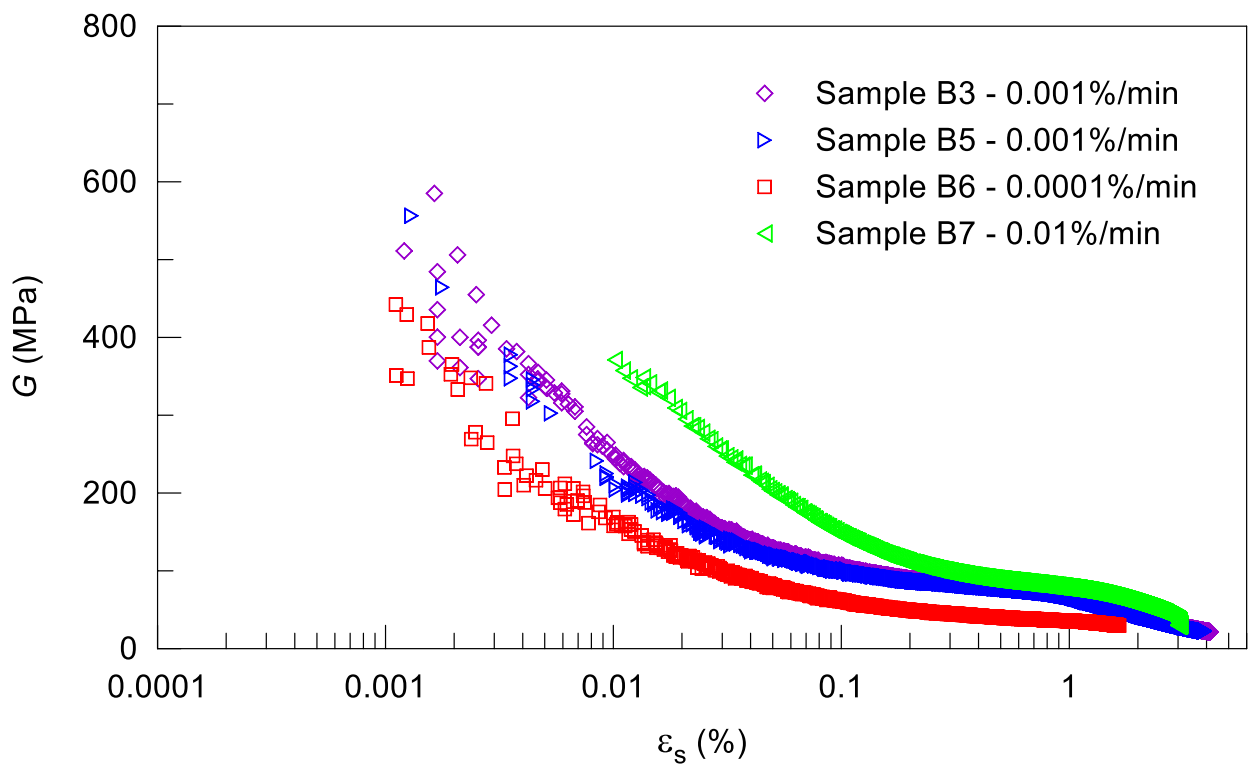

degradation curves, with $G_{0}$ being approximately $20-40 \%$ greater than $G_{\max }$ measured employing local strain gauges. The exception to this is the $1300 \mathrm{kPa}$ mean effective stress test, where $G_{0}$ is approximately equal to $G_{\max }$ derived from local strain data.

\subsection{Effect of Strain Rate}

All specimens used in this study were isotropically consolidated to a mean effective stress of $940 \mathrm{kPa}$, as this stress state represents the approximate change from brittle to ductile behaviour noted in the previous sections. A repeat test at $0.001 \% / \mathrm{min}$ strain rate was carried out on sample B5 (Table 5), to allow for cross-comparison with the test performed on sample B3 discussed in the previous section. A CDT test was carried out at a rate of $0.0001 \%$ per minute on sample B6 and another test was undertaken at a rate of $0.01 \%$ per minute on sample B7 to assess the effect of strain rate.

Stress-strain and volumetric plots are reported in Fig. 11. The comparison between the tests carried out at the same strain rate (i.e. samples B3 and B5) highlights the reliability and repeatability of the testing undertaken. The two plots display a very similar behaviour, despite the samples have been retrieved from different sites and the difference in their depth of origin is more than $24 \mathrm{~m}$. A markedly higher maximum deviatoric stress is observed in the faster $0.01 \%$ / min test along with a brittle strength reduction, whilst the $0.0001 \% / \mathrm{min}$ test shows a significantly less stiff response. It should be noted that the $0.0001 \% / \mathrm{min}$ test had to be stopped prematurely due to time constraints. Whilst all volumetric responses are overall contractant (as discussed for Type $\mathrm{B}$ samples in the previous section), the results indicate a gradual change in behaviour as shearing rate increases, with the slowest test (sample B6) having a continuously contractant response and the fastest test (sample B7) beginning to shift towards a dilatant behaviour after achieving its maximum volumetric strain of $0.7 \%$ at approximately $1.5 \%$ shear strain.

Small-strain stiffness analysis of the CDT results, reported in Fig. 12, show a similar $G_{\max }$ (of proximately 400-500 MPa) for all three rates of strain, although the strain at which stiffness begins to degrade is progressively shifted to the right as shearing rate increases. It can also be noted that the degradation curve of sample B5 is in good agreement with that of sample B3, tested at the same strain rate and initial mean effective stress, thus confirming the repeatability of the adopted testing procedure.

\section{Discussion and Conclusions}

The calcareous mudstones studied in this paper can be considered soft rocks, a material type that displays attributes of both soils and rocks in terms of their mechanical and structural characteristics. All samples looked superficially similar in appearance and bulk properties. The specimens disintegrated rapidly when exposed to water in unconfined conditions during durability and dispersivity tests, but they retained their shape during triaxial testing under confining stress, despite being fully saturated.

From a micro-scale point of view, XRPD analysis showed samples to consist of predominantly clay to silt sized Dolomite grains with minor constituents of Quartz and Feldspar (appearing as rare sand sized grains), Halite (often lining 
grain surfaces) and Palygorskite (a clay mineral occurring within void spaces). Relative abundances of minerals varied significantly, with samples displaying high quantities of Dolomite (88-89\%) and low percentages of Palygorskite (4-9\%), i.e. Type A, having distinctly different mechanical characteristics to samples with higher Palygorskite (10-23\%) and lower Dolomite (73-84\%) quantities (Type B). Moreover, SEM tests revealed the micro-structure of the calcareous mudstones on a granular scale and showed Type A samples to display tightly bonded mosaics of Dolomite grains with small amounts of fibrous Palygorskite within voids. It is believed that continuous dissolution and re-precipitation at the contact points between Dolomite grains has led to their interlocked appearance, probably contributing to their higher strength and stiffness than Type B samples, as seen by Mazzullo (1992) and Jameson (1992). On the contrary, the presence of a greater quantity of Palygorskite in Type B samples is thought to inhibit the processes of dissolution and precipitation, preventing the strong mosaics of Dolomite grains to form.

Particle size distribution and Atterberg limits confirmed the interpretation of the XRPD and SEM analysis, indicating that Type A samples were characterised by lower void ratios, they were typically less plastic and had a smaller percentage of material passing the $2 \mu \mathrm{m}$ grain size fraction than their Type B counterparts, which instead showed higher plasticity and a greater percentage of fines.

In terms of macro-scale mechanical behaviour, the soft calcareous mudstones were observed to have strength and stiffness that are highly dependent upon mean effective stress (similar to the behaviour of hard soils/soft rocks noted by Heymann (1998) and soft sandstones investigated by Kate and Gokhale (1998)) and strain rate (comparable to structured soils (e.g. Leroueil 1998), hard soils (e.g. Silvestri and d'Onofrio 1998) and fine grained soils (e.g. Vardanega and Bolton 2011)). However, significant differences emerged as the triaxial experiments were undertaken, resulting in the identification of two distinct patterns: Type A samples showed a brittle and dilatant response during shearing, while Type $\mathrm{B}$ a more ductile and contractant behaviour. Considering the evidences obtained from the XRPD and SEM testing, it is believed that the presence (or absence) of large quantities of inter-clast Palygorskite within the specimens is responsible for the differences observed in their strength and stiffness response. The decrease in material strength with increased Palygorskite content is thought to be related to earlier diagenetic processes having been inhibited, thus resulting in weaker bonded Dolomite grains. In fact, both Type A and B samples shared a similar effective angle of internal friction at failure and post failure, but Type B specimens showed a lower effective cohesion due to a poorer degree of bonding. This is also reflected on the stiffness response, with the better bonded Type A samples being stiffer than their Type B counterparts at any given mean effective stress. Therefore, Palygorskite relative abundances seem to be a key controlling factor of the overall behaviour of the investigated rocks during shearing.

Concluding, soft calcareous mudstones should be thought of as highly structured/bonded/cemented soils, similar to materials such as Vallericca Clay (Amorosi and Rampello 2007), Pappadai Clay (Cotecchia and Chandler 1997; Leroueil 1998) or even London Clay (Gasparre et al. 2007), in terms of the degree of additional strength and stiffness due to the presence of micro-structure. Deviations in behaviour from structured soils occur in terms of the higher shear stiffness observed at lower mean effective stress, likely caused by the presence of developed bonding/cementation. In terms of practical advice, testing methodologies adopted for these soft rocks should largely follow the framework developed for cemented soils rather than that of rock mechanics tests. In addition, recommendations for further research include non-destructive testing methods, such as Needle Penetration Test, X-ray Computed Tomography Scanning and Infrared Thermography Techniques, which are being increasingly used for the determination of the mechanical properties of soft rocks.

Within this perspective, future work will be focused on the validation and calibration of existing advanced soil constitutive models accounting for structure degradation against the experimental data presented in this paper.

Acknowledgements David Simpson was funded by EPSRC CASE Studentship which was carried out in collaboration with BuroHappold. Peter Scott at BuroHappold is thanked for help with acquiring the rock samples.

Open Access This article is licensed under a Creative Commons Attribution 4.0 International License, which permits use, sharing, adaptation, distribution and reproduction in any medium or format, as long as you give appropriate credit to the original author(s) and the source, provide a link to the Creative Commons licence, and indicate if changes were made. The images or other third party material in this article are included in the article's Creative Commons licence, unless indicated otherwise in a credit line to the material. If material is not included in the article's Creative Commons licence and your intended use is not permitted by statutory regulation or exceeds the permitted use, you will need to obtain permission directly from the copyright holder. To view a copy of this licence, visit http://creativecommons.org/licenses/by/4.0/.

\section{References}

Amorosi A, Rampello S (2007) An experimental investigation into the mechanical behaviour of a structured clay. Géotechnique 57(2):153-166

ASTM (1990) Standard test method for slake durability of shales and similar weak rocks (d4644). In: Annual book of ASTM standards volumes, 4(08) ASTM, Philadelphia, pp 863-865

Aversa S, Evangelista A (1998) The mechanical behaviour of a pyroclastic rock: yield strength and destructuration effects. Rock Mech Rock Eng 31(1):25-042

Brown E (1986) Rock characterization, testing and monitoring: ISRM suggested methods. Pergamon Press, Oxford 
BS1377-2 (1990) Methods of tests for soils for civil engineering purposes-Part 2: classification tests. British Standards Institution, London

BS1377-5 (1990) Methods of tests for soils for civil engineering purposes-Part 5: compressibility, permeability and durability tests. British Standards Institution, London

BS1377-8 (1990) Methods of tests for soils for civil engineering purposes-Part 8: shear strength tests (effective stress). British Standards Institution, London

Burland J, Lord J (1970) The load-deformation behaviour of Middle Chalk at Mundford, Norfolk: an comparison between full scale performance and in-situ laboratory measurments. In: In situ investigations in soils and rocks, Building Research Station

Ciantia M, Castellanza R, di Prisco C (2015) Experimental study on the water-induced weakening of calcarenites. Rock Mech Rock Eng 48(2):441-461

Cook A (1999) The soil to rock boundary for weak calcareous rocks. In: Proc 2nd int conf on engineering for calcareous sediments, Balkema, Rotterdam

Cotecchia F, Chandler R (1997) The influence of structure on the prefailure behaviour of a natural clay. Geótechnique 48(3):523-544

Epps R (2011) Engineering properties of the carbonate sediments along the Abu Dhabi Coast, United Arab Emirates. Int Assoc Sedimentol Spec Publ 43:221-242

Eugster H, Hardie L (1978) Saline lakes. In: Lerman A (ed) Physics and chemsitry of lakes. Springer, Berlin, pp 237-293

Evans G, Murray J, Biggs H, Bate R, Bush P (1973) The oceanography, ecology, sedimentology and geomorphology of parts of the trucial coast barrier island complex, persian gulf. In: Purser B (ed) The Persian Gulf. Springer, Berlin

Fereidooni D (2016) Determination of the geotechnical characteristics of hornfelsic rocks with a particular emphasis on the correlation between physical and mechanical properties. Rock Mech Rock Eng 49(7):2595-2608

Fonseca A, Ferreira C, Fahey M (2009) A framework interpreting bender element tests, combining time-domain and frequencydomain methods. Geotech Test J 32(2):1-17

Franklin J, Chandra A (1972) The slake durability test. Int J Rock Mech Min 9:325-341

Gasparre A, Nishimura S, Coop M, Jardine R (2007) The influence of structure on the behaviour of London Clay. Géotechnique 57(1):19-31

Hawkins A (1998) General report: the nature of hard rocks/soft soils. In: Proc 2nd int symp on hard soils/soft rocks, Balkema, pp 1391-1402

Haydn M, Huitang Z (2005) Palygorskite and sepiolite (Hormites). Clays Clay Miner 76:400-405

Heymann G (1998) The stiffness of soils and weak rocks at very small strains. $\mathrm{PhD}$ thesis, University of Surrey

Inglès M, Anadón P (1991) Relationship of clay minerals to depositional environment in the non-marine eocene pontils group, se ebro basin (spain). J Sediment Petrol 61(6):926-939

Isphording W (1973) Discussion of the occurrence and origin of sedimentary palygorskite-sepiolite deposits. Clay Clay Miner 21(5):391-401

ISRM (1979) Suggested methods for determining water content, porosity, density, absorption and related properties and swelling and slake-durability index properties. Int J Rock Mech Min Sci Geomech Abstr 16:143-151

Jameson J (1992) Dolomite neomorphism and porosity evolution. In: AAPG Search and Discovery Article, Balkema, p 91012

Jeong H, Kang S, Obara Y (2007) Influence of surrounding environments and strain rates on the strength of rocks subjected to uniaxial compression. Int J Rock Mech Min Sci 44(3):321-331
Jovicic V, Coop M (1996) Objective criteria for determining $\mathrm{G}_{\max }$ from bender element tests. Géotechnique 46(2):357-362

Kanji M (2014) Critical issues in soft rocks. J Rock Mech Geotech Eng 6:186-195

Kässler P (1973) The structural and geomorphic evolution of the persian gulf. The Persian Gulf. Springer, Berlin, pp 11-32

Kate J, Gokhale C (1998) Influence of moisture on triaxial compression behaviour of soft sandstone. In: Proc 2nd int symp on hard soils/ soft rocks, A.A. Balkema, pp 245-252

Lagioia R, Nova R (1995) An experimental and theoretical study of the behavior of a calcarenite in triaxial compression. Géotechnique 45(4):633-648

Lagioia R, Burland J, Delage P (1998) Pre-yield behaviour of the gravina calcarenite at small strains. In: Proc 2 nd int symp on hard soils/soft rocks, A.A. Balkema, pp 629-636

Last W (1990) Lacustrine dolomite: An overview of modern, holocene and pleistocene occurrences. Earth Sci Rev 27:221-263

Leroueil S (1998) Contribution to the round table: peculiar aspects of structured soils. In: Proc 2nd int symp on hard soils/soft rocks, A.A. Balkema, pp 1669-1678

Liu Z, Zho C, Li B, Zhang L, Liang Y (2019) Effects of grain dissolution-diffusion sliding and hydro-mechanical interaction on the creep deformation of soft rocks. Acta Geotech. https://doi.org/10. 1007/s11440-019-00823-9

Machel H (2001) Bacterial and thermochemical sulfate reduction in diagenetic settings-old and new insights. Sediment Geol 140:143-175

Mazzullo S (1992) Geochemical and neomorphic alteration of dolomite: a review. Carbonates Evaporites 7(1):21-37

Merkl R (1989) A sedimentological, mineralogical and geochemical study of the fuller's earth deposits of the miocene Hawthorne group of south Georgia-North Florida, Bloomington. $\mathrm{PhD}$ thesis, Indiana University

Neaman A, Singer A (2000) Rheological properties of aqueous suspensions of palygorskite. Soil Sci Soc Am J 64(1):427-436

Pierre C, Rouchy J (1988) Carbonate replacements after sulfate evaporites in the middle miocene of Egypt. J Sediment Petrol $58: 446-456$

Rhouta B, Zatile E, Bouna L, Lakbita O, Maury F, Daoudi L, Lafont M, Amjoud M, Senocq F, Jada A, Ait Aghzzaf A (2013) Comprehensive physicochemical study of dioctahedral palygorskite-rich clay from Marrakech High Atlas (Morocco). Phys Chem Miner 40:411-424

Rietveld HM (1969) A profile refinement method for nuclear and magnetic structures. J Appl Crystallogr 2:65-71

Rodriguez-Navarro C, Sebastian E, Doehne E, Ginell W (1998) The role of sepiolite-palygorskite in the decay of ancient Egyption limestone sculptures. Clays Clay Miner 46(4):414-422

Sanz-Montero M, Rodriguez-Aranda J, Calvo J (2006) Mediation of endoevaporitic microbial communities in early replacement of gypsum by dolomite: a case study from miocene lake deposits of the madrid basin, spain. J Sediment Res 76:1257-1266

Silvestri F, d'Onofrio A (1998) Panel report: advanced procedures in laboratory stress-strain testing on hard soils. In: Proc 2nd int symp on hard soils/soft rocks, A.A. Balkema, pp 1415-1428

Singer A (1981) The texture of palygorskite from the Rift Valley, southern Israel. Clay Miner 16(4):415-419

Truong Q, Lee C, Kim Y, Lee J (2012) Small strain stiffness of saltcemented granular media under low confinement. Géotechnique 62(10):949-953

Vardanega P, Bolton M (2011) Practical methods to estimate the nonlinear shear stiffness of fine grained soils. In: 5 th int sym on deformation characteristics of geomaterials, IOS Press

Viggiani G, Atkinson J (1995) Interpretation of bender tests. Geótechnique 45:149-154 
Walkden G, Williams A (1998) Carbonate ramps and the pleistocenerecent depositional systems of the Arabian Gulf. Geol Soc Spec Publ 149:43-53

Wright A, Burgraeve A, Cathie D (1999) State of practice for site investigation in calcareous sediments. In: Proceedings of the 2 nd int conf on engineering for calcareous sediments, vol 2, pp 433-442
Publisher's Note Springer Nature remains neutral with regard to jurisdictional claims in published maps and institutional affiliations. 